\title{
Flood Risk Modeling of Urbanized Estuarine Areas under Uncertainty: A Case Study for Whitesands, UK
}

\author{
Manousos Valyrakis ${ }^{1^{*}}$, Mark Solley $^{2}$ and Eftychia Koursari ${ }^{2}$ \\ ${ }^{1}$ Water and Environmental Engineering, Research Division of Infrastructure and Environment, \\ School of Engineering, University of Glasgow, UK. \\ ${ }^{2}$ Research Assistant, MEng in Civil Engineering, University of Glasgow, UK.
}

\begin{abstract}
Authors' contributions
This work was carried out in collaboration between all authors. Author MV conceived and designed the study, and wrote the manuscript. Author MS conducted the desk study, model simulations and field visits. Author EK conducted the literature search and formatted the manuscript. All authors read and approved the final manuscript. All authors read and approved the final manuscript.
\end{abstract}

Article Information

DOI: 10.9734/BJECC/2015/12915

Case Study

Received $23^{\text {rd }}$ July 2014

Accepted $13^{\text {th }}$ October 2014

Published $5^{\text {th }}$ June 2015

\section{ABSTRACT}

Aims: The impacts of catastrophic flooding have steadily increased over the last few decades. This work investigated the effectiveness of flood modeling, with low dimensionality models along with a wealth of soft (qualitative) and hard (quantitative) data. In the presence of very low resolution or qualitative data this approach has the potential of assessing a plethora of different scenarios with little computational cost, without compromise in prediction accuracy.

Study Design: A flood risk modeling approach was implemented for the urbanized and flood prone region of Whitesands, at the Scottish town of Dumfries. This involved collection of a wide range of data: a) topographical maps and data from field visits were used to complement existing crosssectional data, for building the river's geometry, b) appropriate hydrological data were employed to run the simulations, while historical information about the extent, depth and impacts of flooding were utilized for calibrating the hydraulic model, and c) a wealth of photographic data obtained during the most recent December 2013 flood, were used for the model's validation.

Place and Duration of Study: Desk study: School of Engineering, University of Glasgow; September 2013 to May 2014. Field study: Dumfries; November 2013 to January 2014.

Methodology: The HEC-RAS 1D model has been used to represent the hydraulics of the system. Flood maps were produced considering the local topography and predicted inundation depths. Flood cost and risk takes further into account the type and value of inundated property as well as the extent and depth of flooding. 
Results: The model predictions (inundation depths and flood extents presented in the flood maps) were in fairly good agreement with the observed results along the studied section of the river.

Conclusion: This study presented a flood modeling approach that utilized an appropriate range of accessible data in the absence of detailed information. As the level of performance was comparable to other inundation models the results can be used for identification of flood mitigation measures and to inform best management strategies for waterways and floodplains.

Keywords: Flood risk modeling; flood protections; Scotland; HEC-RAS; uncertainty.

\section{INTRODUCTION}

Flooding and the catastrophes associated with ithave always presented a major challenge our humanity has to face. Despite a number of measures and policies continuously revised and implemented to tackle it, there still exists a rather worrying trend of increased impacts from flooding. This situation exists primarily due to two main reasons: a) the intensification of storms expressed as an increase of both their magnitude and frequency due to climate change, and b) increased rates of urbanisation, particularly near coasts and estuaries, which are typically more flood prone. The above factors act synergistically if the increased runoff volume (due to limited storage) and the rapid response because of more impermeable ground surfaces are taken into consideration. Given the above situation, it is expected that the world's population will become more and more vulnerable to floods.

\subsection{Flooding: A Global Phenomenon}

According to the 2012 Annual Disaster Statistics Review [1], since the early 1990's water related disasters have risen significantly, with flooding accounting for more than any other disaster type. In particular, over the period from 1985 and 2009 , floods accounted for more than $40 \%$ of all other natural catastrophes worldwide while they have been responsible for $13 \%$ of the deaths and about $50 \%$ of the people affected by all natural disasters [2]. For 2012 alone, even though the number of major hydrological disasters has actually decreased from 177 over the previous year to 150 , floods accounted for $53 \%$ of the victims world-wide, with China being the most affected country, totalling $36 \%$ of them [1].

Further regarding the spatial distribution of flood impacts on a global basis, Asia has been the most affected continent in terms of the destruction caused, followed by Africa, the America's, Europe and Oceania, according to the same review [1]. For the United States, floods cost $\$ 6$ billion [ $€ 4.75$ billion] in property damages, claiming over 100 people's lives annually on average [2,3]. For the UK, the potential risks have been dire as an estimated 5 million citizens and 2.4 million buildings were vulnerable to flooding [4]. A recent report [5] predicts that unless effective action is taken up to 2 billion people were expected to be vulnerable due to climate change by 2050 . In a call to action, Jongman et al. [6], estimated an annual cost of $€ 7 \mathrm{bn}$ for EU by 2050, which rendered improving flood defences about 7 times less costly compared to undertaking flood recovery measures.

\subsection{Flooding in Scotland}

The aforementioned situation has not been much different for Scotland, which as the rest of the UK has experienced significant flood problems [7]. In a 2008 report of the Scottish Government, around 100,000 properties in Scotland were classified as either at risk of fluvial or coastal flooding [8]. Since 1989, the maximum-recorded river flows have been measured on half of Scotland's largest river systems [9]. Scotland has a very high rainfall gradient, which ranges from over $3000 \mathrm{~mm}$ in the west to less than $700 \mathrm{~mm}$ in the East. Fluvial flooding caused by heavy rainfall has predominantly occurred in rivers in the west of Scotland, where Dumfries, the region where this study focuses, is located. This trend is related to an increase in westerly circulation through the 1980's and 1990's, which resulted in strong frontal systems coming in off the Atlantic. In terms of future trends for Scotland, an increase of $5 \%-15 \%$ and $18 \%-20 \%$ for the annual run-off and peak flows is expected respectively, by 2050 [10]. Further, if the same trends were to continue for Scotland an increase of $20 \%$ for the medium to high-level floods would be expected by the 2080's [10]. In addition to storm intensification, Scotland's population is expected to continue to grow (from $£ 5.05$ million [€6.48 million] in 2002 to £5.31 million [€6.81 
million] in 2012 according to the National Records of Scotland, 2013), meaning that if urbanisation is not sustainably managed and measures against flooding are not considered, flooding may become an even more significant cause for concern.

\subsubsection{The town and flooding history of Dumfries}

Having obtained an understanding on recent flood trends world-wide and appreciated the importance of managing flooding appropriately this study focused on Dumfries as the study area for demonstrating the flood modelling framework. Dumfries is the biggest town in the South West of Scotland and is the administrative centre for Dumfries and Galloway. The river Nith runs through the centre of Dumfries, and it includes numerous bridges and other hydraulic structures such as weirs. These may be of high functional importance, such as the Buccleuch street bridge (built in 1794) and the St Michael's bridge (constructed in 1925), while other bridges are mainly of historical importance such as the Devorgilla bridge (built in 1432). Dumfries has a rich cultural and historical heritage, thus being attractive to many international visitors. Ensuring the alleviation of major flooding is therefore important not only for the resiliency of the town, but also for its economy and preservation of cultural heritage.

Unfortunately, flooding has also been part of Dumfries history throughout the town's development, a trend that continues into the recent years. Major floods have occurred in 1936, 1962, 1977, 1982 and 2009 and most recently in December 2013.Since the $18^{\text {th }}$ Century, the extent of flooding (as documented stream level gauges) in the area has significantly increased [11]. Of particular interest are the most recent inundation events, as follows. The flood of 2009 lasted from the $19^{\text {th }}$ to $25^{\text {th }}$ November (6 days), after an Atlantic weather front became stationary over the South West of Scotland resulting in prolonged rainfall. The relevant rainfall gauges at Friars Carse (situated just north of Dumfries) and Fiddler's Ford (main tributary to the river Nith) recorded an estimated flood return period of 1 in 10 years and 1 in 26 years respectively. The flood of December 2013 was caused by a heavy and sustained storm event over the South West area of Scotland. This flood was significantly greater than that of 2009 with flood return periods at Friar's Carse and
Fiddler's Ford measured to be comparable to the 1 in 20 years and 1 in 25 years events. A total of 110 floods have been recorded since 1997 in Dumfries, with over half of them being fluvial in nature.

In addition to the increase of frequency and magnitude of storms, a contributing factor to increasing the flood extent and the level of damage caused, might be the reduction of the river's width (e.g. the Devorgilla bridge previously spanned the channel width with 13 of its arches, as opposed to only 7 currently, [11]) and floodplain urbanisation. Furthermore, attempts made by farmers located upstream of the town to protect their crops by diverting the river's flow, may exacerbate the situation [11]. With flood concerns increasing, efforts to decrease the vulnerability of urbanised regions to such events have to continue to prevent such destruction and devastating events from becoming more frequent.

\section{METHODOLOGY}

\subsection{Flood Risk Modeling Under Uncertainty}

Given the gravity of this challenge, flood risk has been extensively studied over the last few decades, many times without success given the array of complexities involved [12]. Here a novel, low cost and easy to implement flood risk modelling framework is presented focusing on the impacted communities ("from the people, for the people") and utilising sound fundamental principles for informing decision making under uncertainty. The framework is summarised in the following phases: a) data gathering, b) hydraulic modelling, c) options assessment, d) informed and collaborative decision-making.

\subsubsection{Data gathering}

In order to understand how the flooding of the river occurs, it is imperative to gain a greater understanding of the river system behaviour. Relevant data that can be used as input to the hydraulic model include the regional climate and the catchment's hydrologic features from which flow discharges for a range of return periods up to 200 years can be utilised. Soft or hard data that can be used directly or can inform the generation of the cross-sections for the hydraulic model geometry, hydraulic roughness, and pairs 
of stage-discharge levels that can be used as boundary conditions to the hydraulic simulations are of utility.

To this goal information from local agencies (such as SEPA, the Met Office, NERC's British Atmospheric Data Centre) and engineering firms that might have surveyed the area, aerial photographs (over different temporal periods), topographic maps and site visits can be used to gain a better understanding of the main channelfloodplain interaction. Here the role of people in soft data gathering cannot be overstated. A wealth of such data, from qualitative statements to photographic documentation containing metadata (e.g. date and geo-location) so that they can be associated to a certain hydrologic event, can be found online or can be gathered by means of crowdsourcing given advances in current technologies significantly simplifying the social sharing of potentially important information across a wide spatial range.

Collecting data towards building a local inundation database finds utility in improving the flood hazard information and helping construct flood maps $[13,14]$. Similarly earlier studies such as by Pretorius et al. [15] and Sothea et al. [16] have utilized human resources to observe and collect data for flooded areas for a large watershed in South Africa and for storm-water runoff and localized urban flooding in Phnom Penh, respectively. Here soft data made available online from community members as well as individuals who took part in this study are utilized.Combining quantitative (hard) data with qualitative (soft) or empirical information collected in this way can help further develop and calibrate the hydraulic model.

\subsubsection{Hydraulic modeling}

Predictions regarding future flooding even though well supported by advanced computational models yet involve significant uncertainties given input assumptions and complexities of weather forecasting especially in the context of climate change $[14,17]$. Considering these uncertainties, as well as uncertainties in flood routing and the representativeness of the hydraulic model geometry utilizing high performance computing and advanced algorithms might not yield more accurate predictions, compared to using simple and low cost computational models. In this case of data limited predictions simple and low dimensional models might work with the same acceptable order of accuracy and most importantly with a lower cost. Onedimensionalhydraulic models can simulate the hydraulics (stage-discharge) of a stream if a sequence of cross-sections representative of its geometry along with other features (such as hydraulic roughness for the main channel and floodplains), are offered as input [18]. It is well known that these models have certain limitations compared to higher dimensionality models [19], which can restrict their utility. This may be particularly true in the case of channels that are very wide, steep or exhibit significant longitudinal variations in their cross-sectional geometry.

However, a great advantage of the onedimensional numerical tools is the significantly lower simulation time required. Such models are rapid to use and require relatively minimal computational time (compared to their 2 or $3 \mathrm{D}$ counterparts), allowing for a wide range of different scenarios to be run promptly, towards efficient decision support. Thus solutions can be reached for various hydrologic events (considering also alternative climate change scenarios) and different types or causes of flooding, while allowing to easily modify the channel's geometry (dredging), add hydraulic structures, embankments, levees, flood walls, upstream storage schemes or any combination of their implementation. Their simplicity, short time to results and wide user community are significant advantages for their utilisation, particularly when a wide number of alleviation scenarios have to be evaluated [20].

Here one of the widely utilized in engineering practice, one-dimensionaland non-commercial program HEC-RAS, is employed for developing and calibrating the hydraulic model. HEC-RAS has been developed by the U.S. Army Corps of Engineers and can be freely downloaded from the following website: http://www.hec.usace.army.mil/software/hecras/downloads.aspx. Further within the program's ability is the potential to compute steady or unsteady flow water surface profiles; conduct sediment transport calculations (even though of relatively limited accuracy [21]) and water quality analysis [22]. The model's geometry is built and calibrated using information collected from the previous stage (as demonstrated in the results section). A range of results (from water surface profiles to flood maps) based on sound first principles and informing about the flood extent and inundation depth for various scenarios of interest can be generated fast. Thus the efficacy 
of a plethora ofdifferent flood mitigation schemes and counter-measures can be evaluated in a relatively shorter period of time, facilitating decision-making by hierarchically representing them [23].

\subsubsection{Options assessment}

Once a number of potential measures have been investigated it is important to evaluate their effectiveness in countering or mitigating flood risk. Effective flood management strategies should incorporate pre-flood counter-measures, high preparedness systems, and post-flood recovery measures $[24,25,26]$. Pre-flood measures refer to preventive works such as direct flood defenses (flood-walls), modification of the channel cross-section (e.g. via dredging), indirect measures (flood storage schemes $[27,28])$ or a combination of these. Land use regulations and urban planning [28,29] considering the flooding potential (e.g. via consultation of flood maps) can help reduce the potential risk of extreme floods. High preparedness systems require robust flood forecasting using real time hydrologic data (including the rainfall, river flow and meteorological parameters) along with effective warning systems that help decrease the exposure of vulnerable population and properties to flooding, thus increasing resilience. It is important to note that proactive rather than reactive measures should have greater priority [30].

\subsubsection{Scientifically informed and collaborative decision-making}

Using a robust and adaptable inundation model requiring less effort and time to set up and configure towards modelling different scenarios significantly enhances the potential for decisionmaking $[23,30]$. However, in addition to considering flood risk prevention and mitigation measures, educating the communities about flood riskcan aid disaster management, as shown in the Netherlands [31]. It is important to emphasize the role of non-governmental or private organizations as well as the public, via local community consultations in addition to government's or local authorities [28,29,30,32]. Involving a wider range of stakeholders by means of improving access to data and models, sharing and communicating flood risk is essential for integrated flood risk management $[12,33]$. Even though during this study there were not enough resources to allow direct feedback from and back to the wider community, there remains a good potential to do so in the near future, particularly with the involvement of the local authorities. Here the data used to help build and verify the hydraulic model can also be used to demonstrate the tangible impacts of local catastrophes, improving individual awareness, informing the public and encouraging social participation.

\subsection{Framework Implementation: The Whitesands Case Study}

\subsubsection{Regional hydrological features and the study area}

The river Nith itself is the largest river in the South West of Scotland, and the $7^{\text {th }}$ largest in Scotland. The catchment area of river Nith covers a total of $1,230 \mathrm{~km}^{2}$, stretching from New Cumnock in South Ayrshire to the South of Dumfries in Glencaple [11] and Fig. 1a. Regarding land use, river's Nith catchment consists of $10 \%$ coniferous forest as well as hill pasture, rough grazing and mixed farmland. There are numerous tributaries of which the most important are the Cluden Water (located upstream of the river) and the Scar Water (around $24-25 \mathrm{~km}$ north of Dumfries).The main floodplains of the river are situated just north of Dumfries in Auldgirth and near the Scar water towards Thornhill (Fig. 1a). There are also a few Sustainable Urban Drainage Systems (SUDS) in and around Dumfries, notably at the housing development in Auldgirth and Lochfoot, the Cuckoo Bridge Retail Park and the Crichton (see Fig. 1a).

Dumfries, being in the south western part of Scotland, receives higher levels of rainfall than the eastern part. An increase in the average monthly rainfall to $1429 \mathrm{~mm}$ over the winter months and greater inter-seasonal variability has been witnessed within the catchment, compared to past decades [11]. The river Nith also offers spawning ground for salmon and other fish species, so unavoidably its ecological function is strongly interlinked with the river's hydrology.

Two out of 23 "potential vulnerable areas" with regard to flooding are located in Dumfries and Galloway, as identified by the Scottish environmental protection agency (SEPA). As the river runs through the centre of Dumfries, flooding can severely impact any infrastructure 
located near or on its flood plains spanning an area of about $116 \mathrm{~km}^{2}$, from the north of Lochmaben to the coast (Fig. 1a). In the recent past 493 residential and 128 commercial properties have been affected, in addition to transport infrastructure and agricultural lands. The annual average cost from such catastrophes is estimated from SEPA to 5 million pounds.

The presented framework is implemented focusing on perhaps the most vulnerable section of Dumfries' centre, which river Nith cuts through, known as the Whitesands (Fig. 1b). Design flow rates for river Nith can be offered for a range of return periods of interest from theNatural River Flow Archive (Centre of Ecology and Hydrology and [32]). To compute the total flow through the Whitesands, the discharges from the Friars Carse gauge station (situated about 10km upstream of the Whitesands) and the Cluden Water gauge station (a tributary to the river Nith situated downstream of Friar's Carse) were combined [34]. At this region, important infrastructure in the vicinity of the river can be discerned from North to South, including the Buccleuch street bridge, the Devorgilla's bridge, the main bus station, the Robert Burns Centre, an open space car park, a business zone near the river's edge, a suspension pedestrian bridge and the St. Michael's (A756 road) bridge (see Fig. 1b). Whitesands has been significantly impacted from both an environmental and a socio-economical perspective, with many homes destructed, local businesses affected and extensive main roads and car parks closures. Even though there have been a number of consultations and technical reports regarding the choice of flood mitigation options, the focus of this study is in demonstrating the utility of the presented framework, under which flood maps can be constructed with limited data. In the following it is further demonstrated how utilising information from aerial photographs, topographical maps and site visits, can be used to produce flood risk maps for the study area, that could be used to evaluate effective flood mitigation schemes.

\subsubsection{Hydraulic model}

Hydraulic modelling typically requires extensive river surveys in which specialised equipment is utilised to acquire accurate values for the river geometry, measure flow rates and the water surface elevations. In the absence of detailed measurements, cross-sections of the river-bed and flood plain can be estimated rather than be precisely produced. It is the premise of this work that by utilising a sufficient range of data, the level accuracy will not be more limited to using a low (such as 1D) dimensional hydraulic model. In order to obtain a representative hydraulic geometry for the studied area, it is important utilise a wide range of potentially relevant information.

In this case study, limited hard data are complemented with soft information from various sources and site investigations to reproduce the hydraulic model's geometry of acceptable level of accuracy. This involves limited quantitative data from a recent SEPA survey and topographical data from UK's Ordnance Survey (OS) Open Data as well as qualitative information from a field trip (before the Dumfries flood of December 2013), archived historical data and satellite imagery. First, the regional topography is investigated with the OS maps (Fig. 2a). As the map's resolution (5-10 m contours) may not be sufficient to reproduce detailed cross-sections for the riverbed and floodplains, the cross-section (Fig.2b) obtained during a most recent river survey is utilised to this goal (Menzies I., Jacobs, personal communication; 17/12/2013).

From inspection of the available cross-sectionit can be clearly seen that that the Mill Green area floodplain, is more prone to flooding (empirical information), while other features such as local slopes can be extracted. Combining this information with the general topography of the area and assuming that the riverbed follows a constant elevation gradient (extracted from the topographic maps), more cross-sections can be constructed to comprise the hydraulic model geometry. The detailed cross-section is used as a template from which nearby cross-sections are developed, making channel adjustments as necessary, informed from data and georeferenced photographs obtained during the site investigations or online (e.g. via Google street view adjustments may include the river's width, where the river's boundary may be found by means of interpolation between contour lines of known elevation above ordnance datum (AOD), and the river bank and floodplain slopes (by means of observation of a photographic archive obtained during the first site visit conducted in November 2013). 


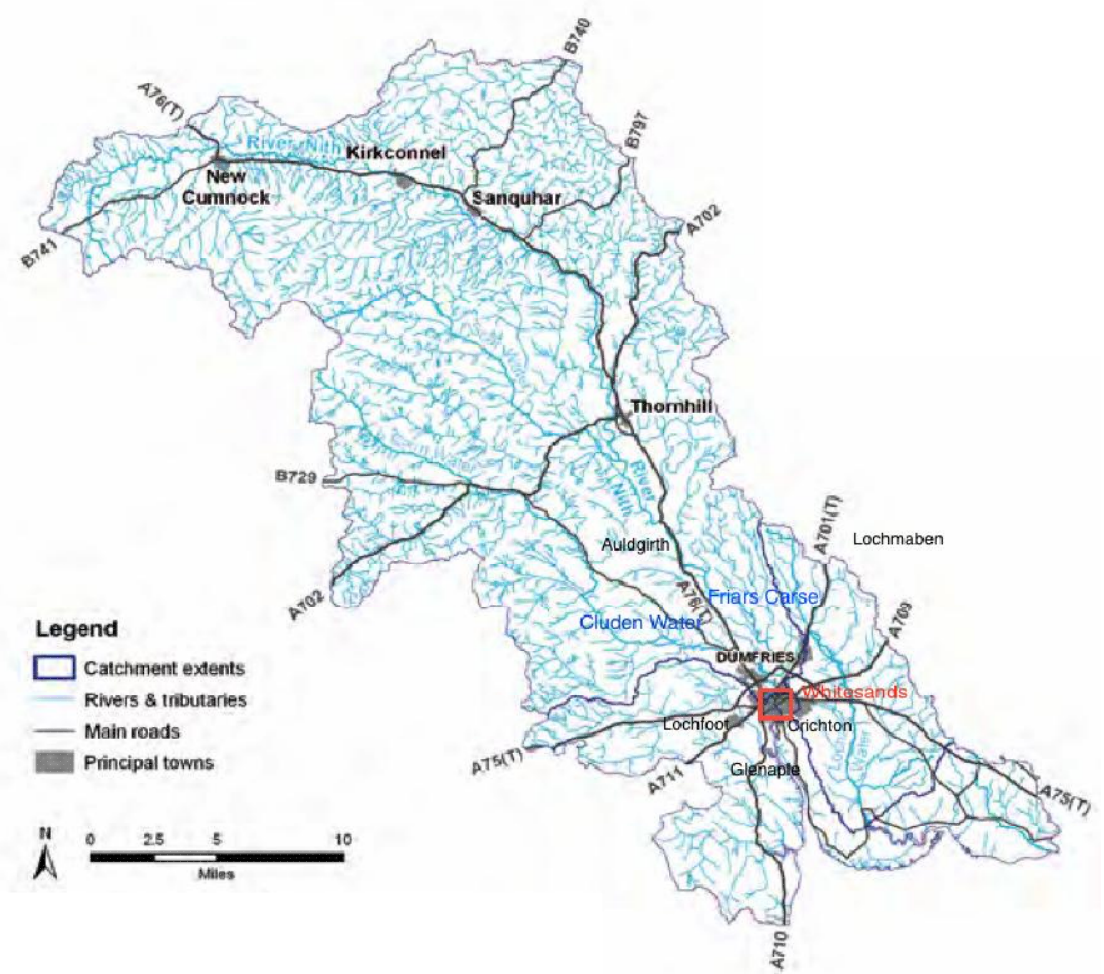

a)

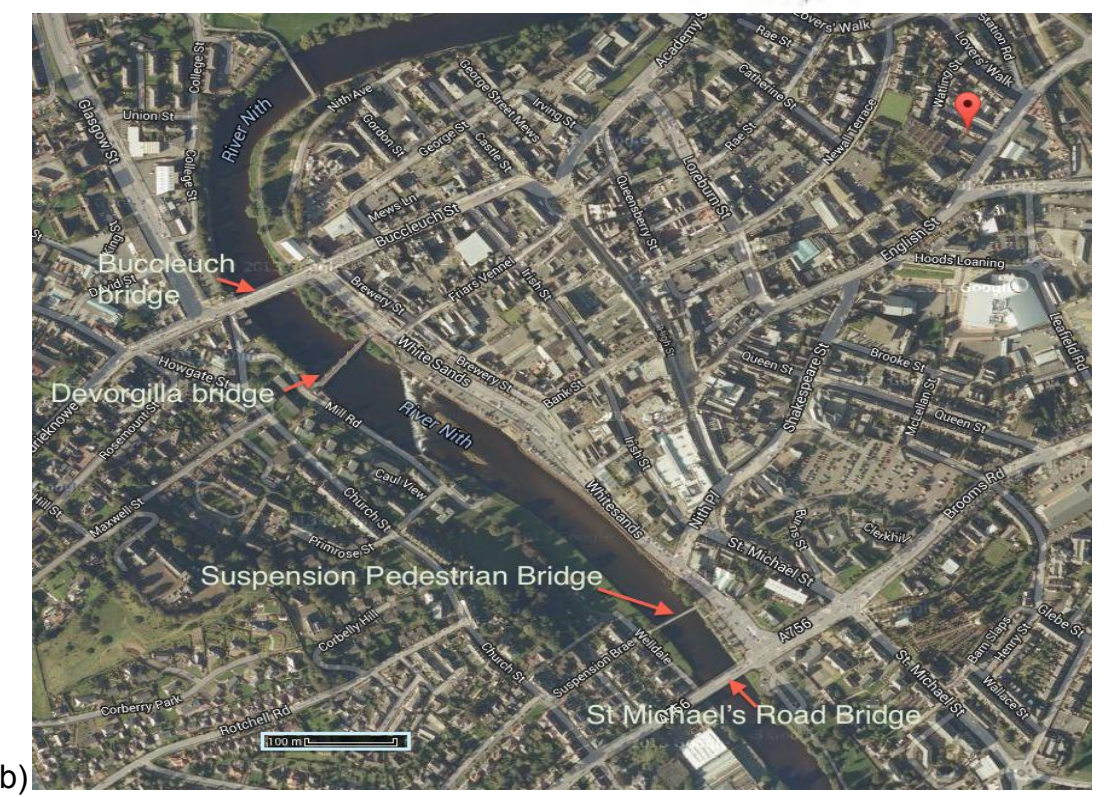

Fig. 1. a) River Nith catchment, showing approximate locations of interest (modified from SEPA 2006) and b) satellite map of the study area (Whitesands), with the Dumfries city center shown as a red pin (source: Google Maps $\odot$ 2014)

Applying the above principle, consecutive crosssections may be built as shown in Fig. 2c. A total of twelve cross-sections were designed, at locations were a specific change in channel geometry occurs or a certain structure such as bridge piers or weirs are present (see annotations in Fig. 2a and examples of the crosssections in Fig. 2c), affecting the water surface elevation. Utilising historical data from archives such as newspapers offering information about 
the extent of flooding and photographic material (such as those utilised from the second site visit carried out during the floods of December 2013), the geometry and hydraulic parameters such as Manning's " $n$ " hydraulic roughness, may be further calibrated (here the final model employs an " $n$ " value of 0.026 and 0.035 for the main channel and floodplain respectively).This thorough process not only facilitated the creation of an accurate hydraulic model, but also enabled a much stronger understanding of the channel and the nature of the surrounding flood plain to be found, which can further inform the impact analysis and decision of mitigation measures.

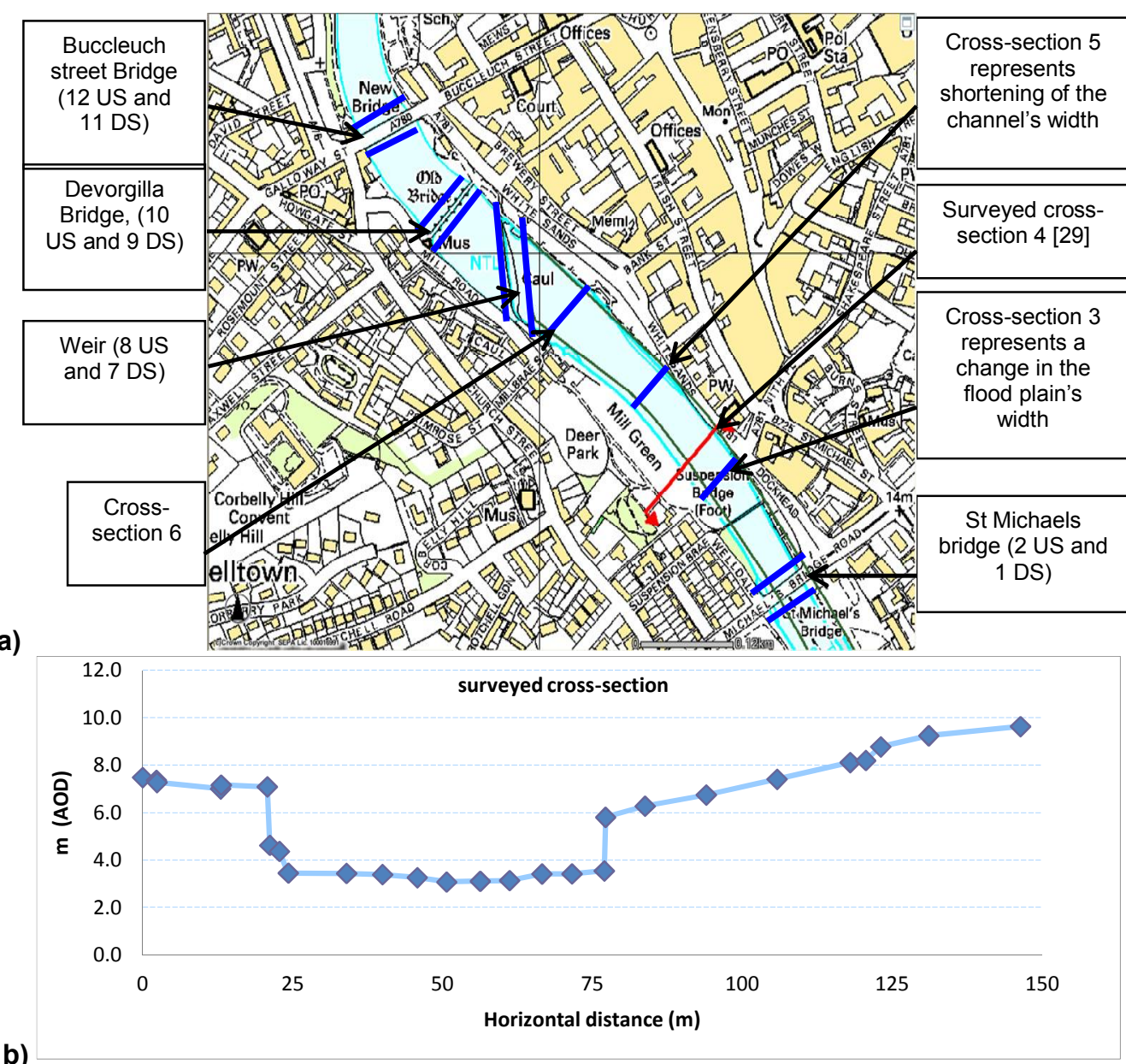

b)

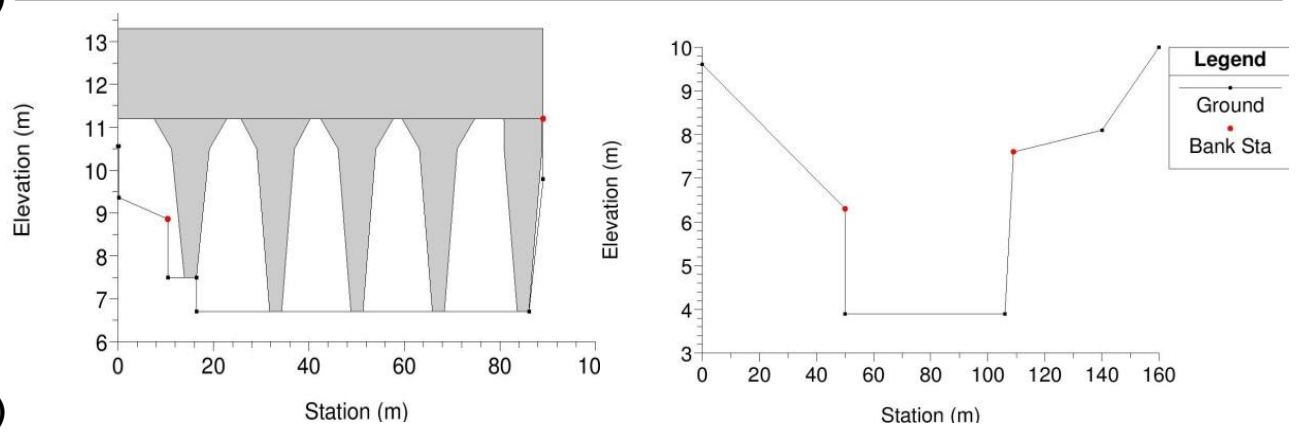

Fig. 2. a) Topographic map of the study area, showing the chosen location and numbering for the hydraulic model's cross-sections,b) the surveyed cross-section 9, and c) demonstration of cross-sections 12 (left image) and 5 (right image) developed in HEC-RAS usinga combination of soft and hard data 


\section{RESULTS AND DISCUSSION}

\subsection{Model Simulations}

The constructed hydraulic model can be run in HEC-RAS using the mixed flow regime (allowing for both subcritical and super-critical regimes to develop along the river).Both the flow regime, upstream and downstream boundary conditions were obtained by using basic hydraulic principles and a trial and error process, ensuring the best representation possible for the flood extent given observed information. Four different scenarios representing floods with return periods of 10 years, 50 years 100 years and 200 years (which is the requirement for flood risk assessment as set out in the Scottish planning policy of 2010), are simulated. Flow discharges of $706 \mathrm{~m}^{3} / \mathrm{s}, 959$ $\mathrm{m}^{3} / \mathrm{s}, 1,093 \mathrm{~m}^{3} / \mathrm{s}$ and $1,246 \mathrm{~m}^{3} / \mathrm{s}$ [32], with the downstream boundary condition set to $2.95,3.4$, 3.9 and $4.3 \mathrm{~m}$, were considered for each of these events respectively (subcritical regime used here with sufficient accuracy). The model computations were completed in a few seconds for all runs.

Fig. 3 demonstrates the computed steady state water surface profile along the stream simulated for various hydrologic events. It can be observed that there is typically a lowering of the flow depth past flow obstructions such as bridge piers, which relatively quickly stabilises following a hydraulic jump. The model further allows viewing the inundation depth and extents, for each crosssection (see Fig. 4). For several of these locations the river covers the floodplain for a significant distance, potentially affecting many properties and infrastructure. For example, the region of Whitesands is seen to flood to a great distance beyond the riverbank (about $100 \mathrm{~m}$ laterally). The same holds true in the case of Mill Green, where the left river-bank can flood even for the 10 year return period. Similarly, St Michael's bridge is estimated to be overtopped for return periods of 100 and 200 years (Fig. 4c).

Utilising the above results flood maps for the range of simulated scenarios can be developed, considering the local topography and predicted inundation depth. An example is offered in Fig. 5 where the extents of flooding are overlaid on the available topographic map (e.g. using ArcMap). It may be observed that the inundation extents are gradually expanding for hydrologic events of greater extremity, clearly demonstrating which areas and under which types of land use are under greater risk of inundation.

Flood cost and risk can be further quantified by taking into account the type and value of inundated property as well as the extent and depth of flooding. The largely catastrophic flood events are those with higher extremity (both infrequent and greater magnitude) and flood risk should be evaluated for such events ( 1 in 200 for Scotland, 1 in 100 for the rest of the UK). However, the results from simulations with smaller return periods (e.g. 1 in 10 or 50 years) can be also useful if past observations of the flood depth and extent are available for such events, allowing comparison and model verification.

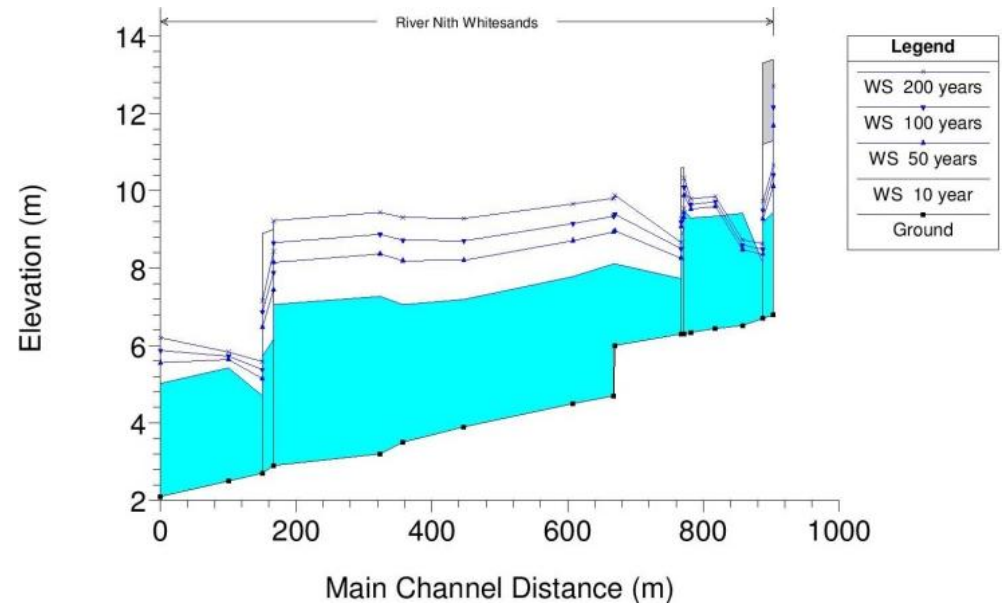

Fig. 3. Profile plot demonstrating the water surface elevation computed at the chosen crosssections along the river Nithat Whitesands, for mixed flow boundary conditions and for a range of return periods (from 10 to 200 years) 


\subsection{Model Verification}

According to the presented framework, soft data inclusive of data gathered from various sources (e.g. archives or online) as well as a rich photographic archive and information during the field trip, may be used here to evaluate the performance of the hydraulic model. As an example Fig. 6a depicts an impression of the Devorgilla's bridge from artist Robert Andrew Riddell c 1780 that can be found at Dumfries museum. Such historical information can be used to realise changes in the bed geometry and land use that may have occurred recently and how this might be affecting flooding. In particular, comparing this portrait (Fig. 6a) with a contemporary image (taken during the November 2013 site visit) from about the same viewpoint, one can clearly observe that the river width is now shorter, spanning only 7 arches compared to 10 in the past. Further comparisons can be made between the model results (Fig. 3) and known hydraulic conditions during an observed event such as the December 2013 flood (Fig. 6c). Considering that the December 3013 flood corresponds to roughly a 1 in 25 years event, the distances of the water surface elevation from the top of the arcs inferred from Fig. $6 \mathrm{c}$ (about $1.5 \mathrm{~m}$ ) are within the range of those predicted for the 1 in 10 and 1 in 50 years flows (1.7 and $1.32 \mathrm{~m}$ respectively), providing assurance for the accuracy of the hydraulic model.

a)
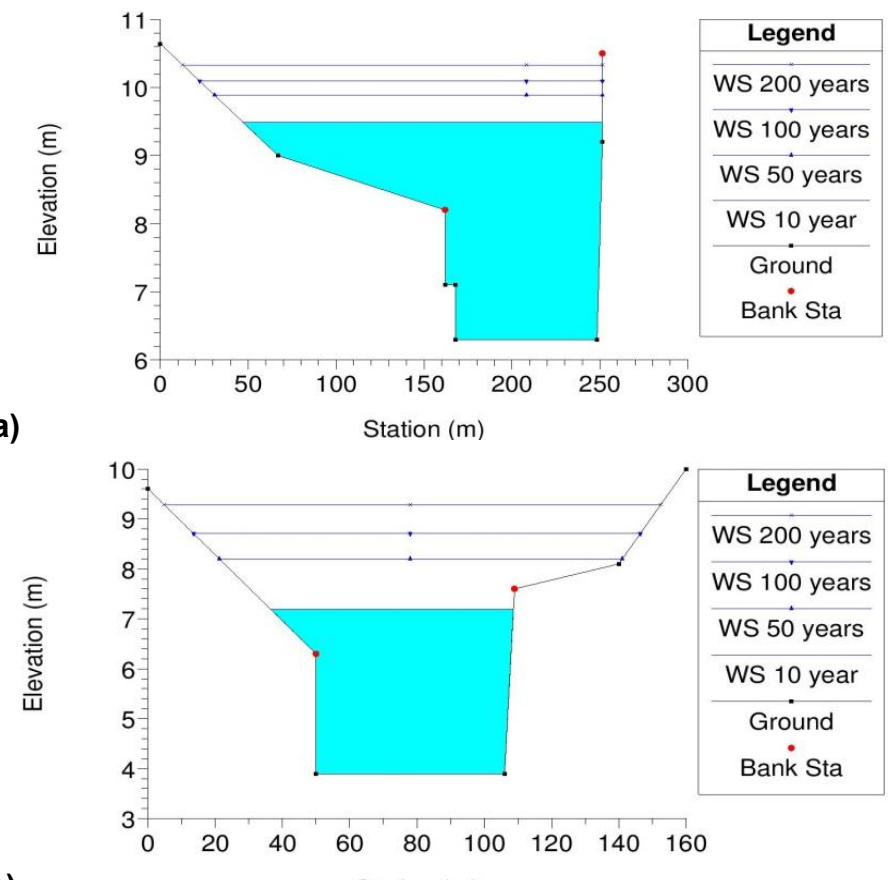

b)

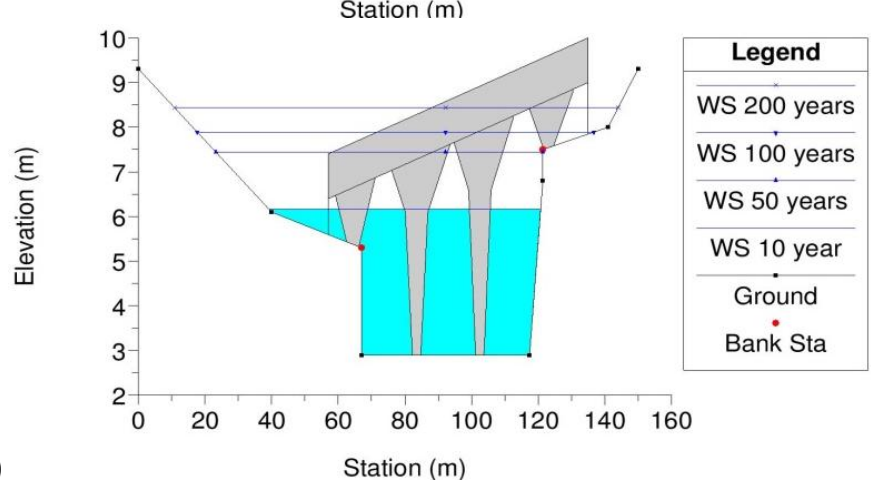

Fig. 4. Computed water surface elevations for the hydrologic scenarios of interest (return periods shown in legends) for cross-sections: a) 10 (Whitesands), b) 5(Mill Green) and c) 2 (St Michael's bridge) 


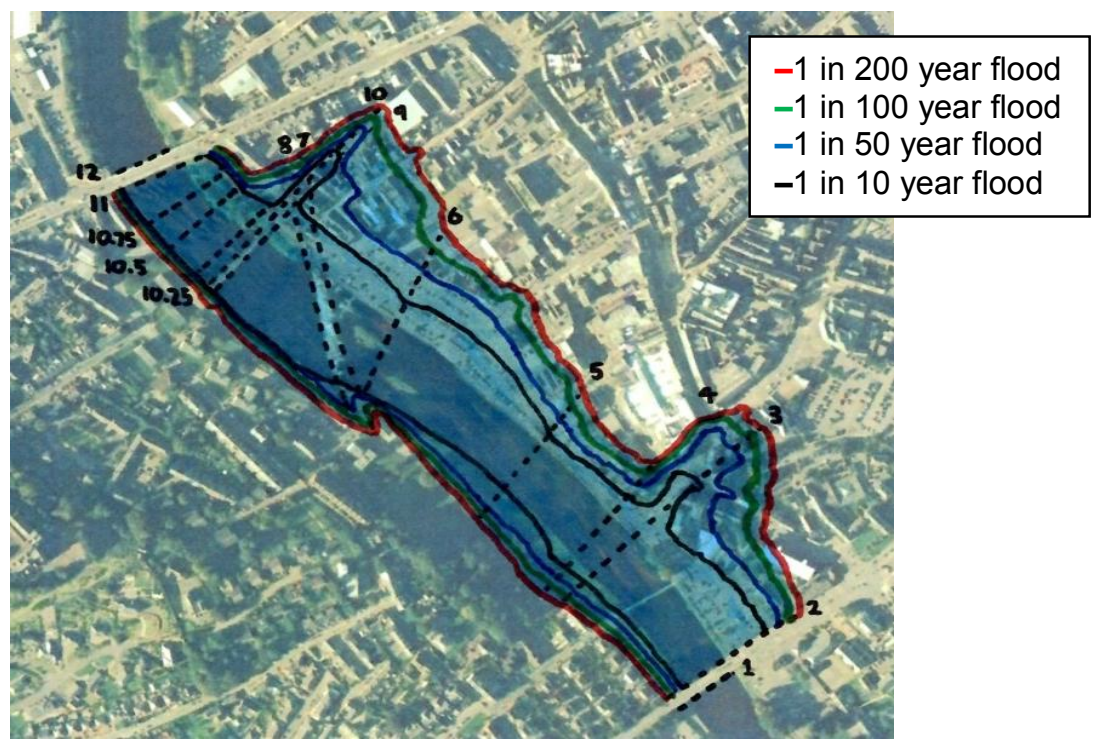

Fig. 5. Flood map demonstrating the extents of flooding for each return period (shown in the legend). The dashed numbered lines show the location and span of the used cross-sections

a)

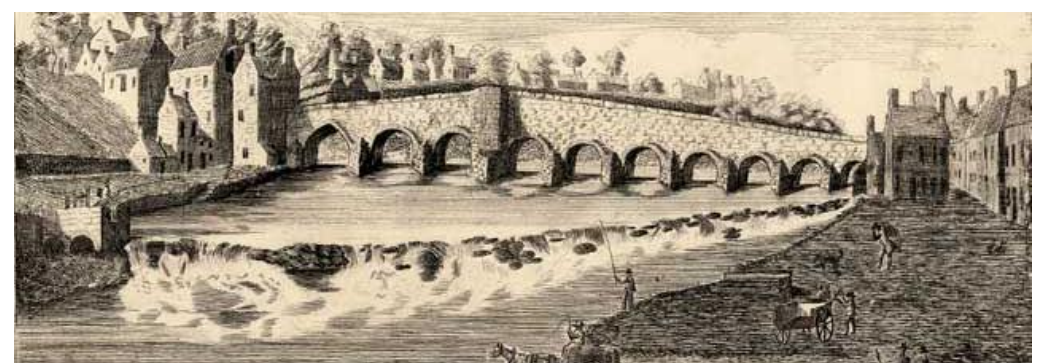

b)

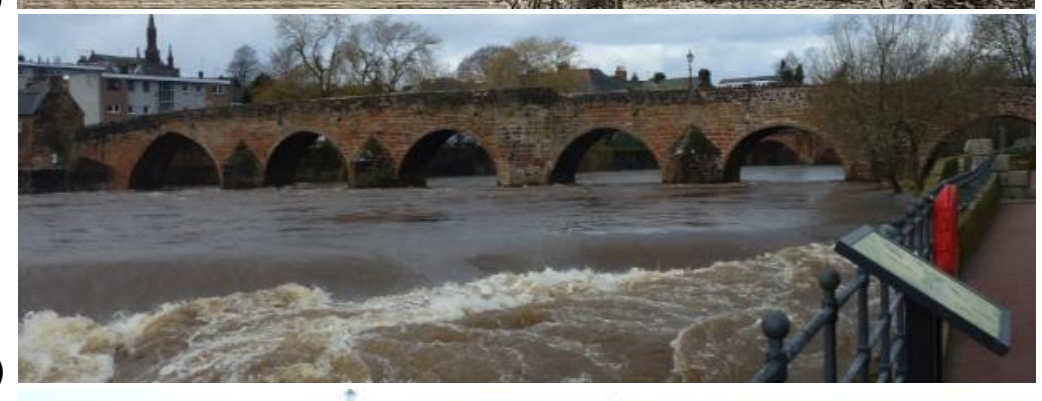

c)

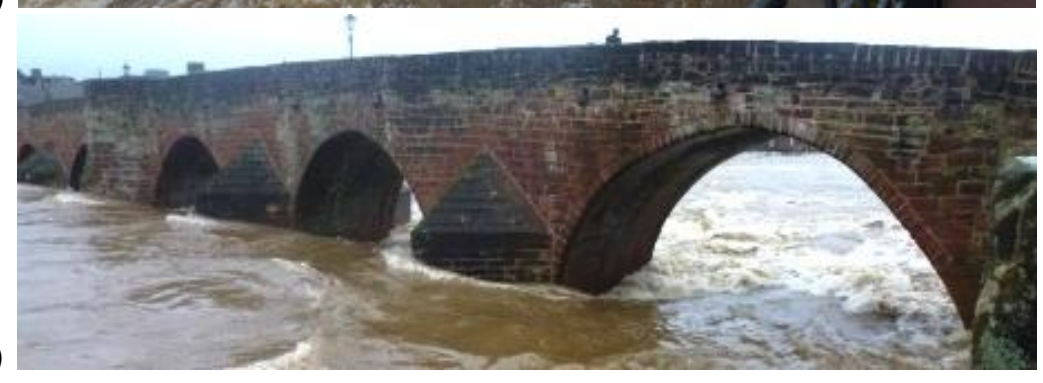

Fig. 6. The Devorgilla's bridge and downstream weir: a) historical representation of from downstream (from painter Robert Andrew Riddell c 1780, at the Dumfries Museum), b) preflood (November 2013) photograph from downstream, and c) photograph from upstream during the December 2013 flooding 
Proceeding in the same manner and utilising available information for more locations where the water surface height is predicted (e.g. those shown in Fig. 4), can be utilised to verify the model's performance. As an example,for crosssection 10, a greater flood extent (ranging from $112 \mathrm{~m}$ to $130 \mathrm{~m}$ for the floods of 1 in 10 and 1 in 50 years respectively) is seen for the floodplain corresponding to the area of Whitesandswhich (Fig. 4a). This is validated with the photographic evidence presented in Fig. 7b (for the December 2013 flood), showing an approximate lateral extent of flooding of about $120 \mathrm{~m}$ from the riverbank. Further comparisons with photos of the same area when not inundated (e.g. from Google street view (c), Fig. 7a) may be used to deduce the depth of flooding, which is relevant in flood risk and costing estimations.

Similar comparisons can also be made at the downstream cross sections. At the flood plain at the Mill Green area (Fig. 8a), a flooding extended to about $15 \mathrm{~m}$, as witnessed during the site investigation and illustrated in Fig. $8 \mathrm{~b}$ below. This is replicated in the results of the hydraulic model (see cross section 5, Fig. 4b) where a strip of

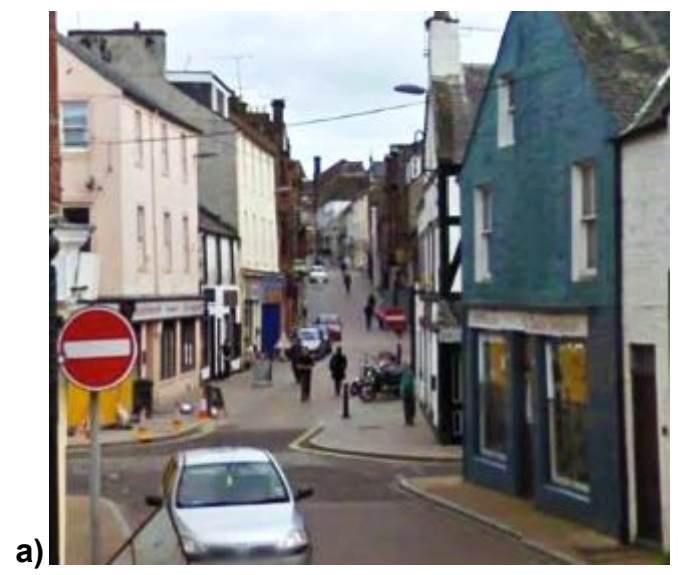

land of about $20 \mathrm{~m}$ is inundated for the 1 in 50 year return period (also Fig. 5). Finally, it is quite notable to observe that during the December 2013 floods, St Michael's bridge had nearly flooded. In this instance, the first pier to the east was completely submerged, with the deck of the bridge still visible (Fig. 8d). For this case, the hydraulic model predictions are in accordance with the above observations with half of the $1^{\text {st }}$ bridge pier submerged for the 1 in 10 year flood and the bridge deck is submerged for the 1 in 50 year return period (Fig. 4c).

Such comparisons between the hydraulic model predictions and available data, for a range of hydrologic events, are effectively utilised in validating the model's accuracy throughout the reach. The resulting model can be used to assess the impacts and cost of flooding, towards efficient management and mitigation of the flood events [35]. This framework is robust and low cost, allowing for the rapid evaluation of a range of possible flood mitigation schemes and counter-measures, which may facilitate decisionmaking.

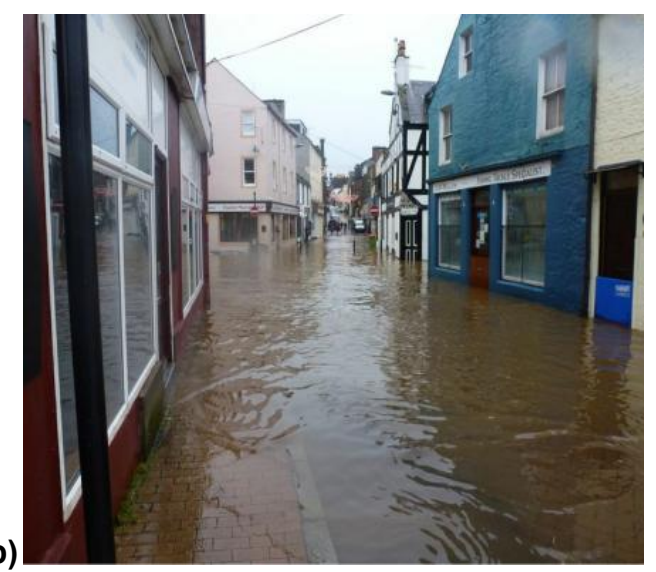

Fig. 7. View of Friars Vennel street from Whitesands street: a)before flooding (Google street ( ) view, November 2010) and b)during the December 2013 flooding

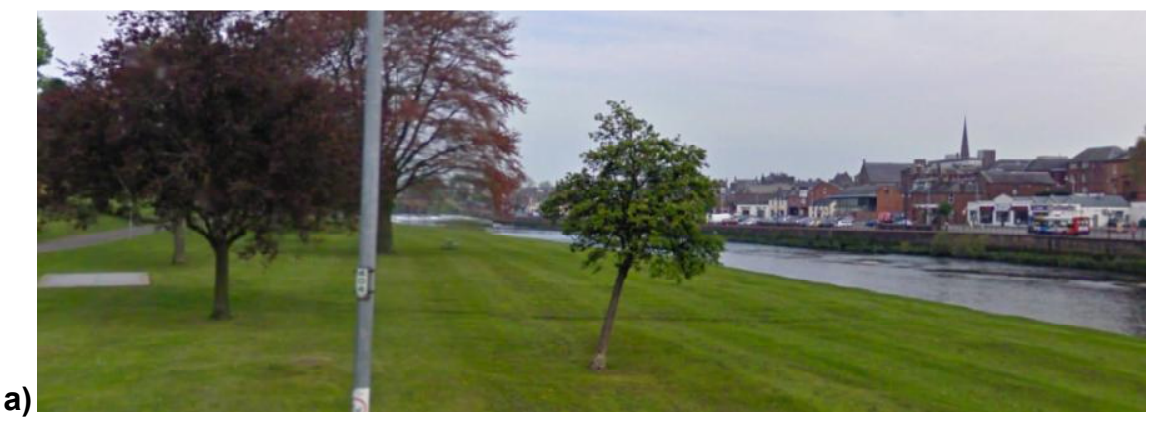




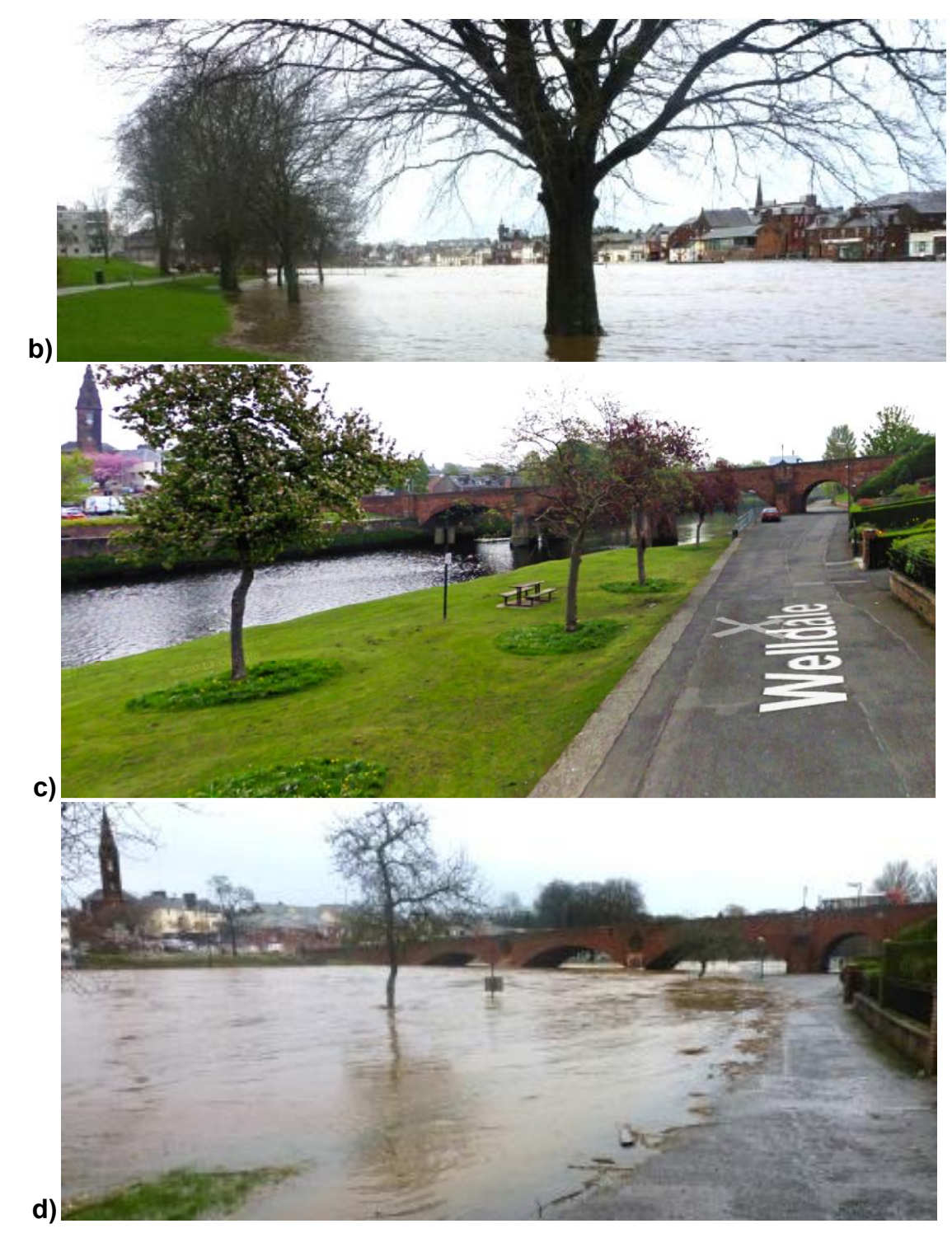

Fig. 8. View from Welldale street - looking upstream to Mill Green: a) before flooding (Google street (c) view, April 2009) and b) during the December 2013 flooding, and looking downstream to St Michael's bridge: c) before flooding (Google street $\odot$ view, April 2009)and d) during the December 2013 flooding

\section{CONCLUSION}

In this study an integrated flood risk modelling framework is presented for effectively tackling the increased uncertainties associated with it. This methodology involves utilisation of a wide range of hard and soft data (data gathering) from a variety of sources that can be combined towards the development and calibration of the hydraulic model. Low-dimensional hydraulic modelling is chosen due to its robustness, adaptability, short time to results and ease of use. The model can aid decision-making, focusing primarily on prevention and management measures, which can be evaluated and ranked based on performance, and involving the public and other stakeholders via consultations.

The modelling framework is successfully implemented to the region of Whitesands in Dumfries, UK. The predicted inundation depths and extents for a range of hydrologic events of interest demonstrate the flood impact to the 
region. These results are further validated with appropriate analysis and comparisons with photographic documentation obtained during the flood event of December 2013, thus may be used with confidence for identification of appropriate flood mitigation measures.

\section{ACKNOWLEDGEMENTS}

Funding from the School of Engineering, at the University of Glasgow is gratefully acknowledged.

\section{COMPETING INTERESTS}

Authors have declared that no competing interests exist.

\section{REFERENCES}

1. Guha-Sapir D, Hoyois PH, Below R. Annual Disaster Statistical Review 2012: The Numbers and Trends. Brussels: CRED; 2013.

2. Atreya A, Ferreira S, Kriesel W. Forgetting the Flood? An Analysis of the Flood Risk Discount over Time. Land Econ. 2013;89(4):577-596.

3. U.S. Geological Survey (USGS). Flood Hazards: A National Threat. U.S. Geological Survey Fact Sheet. 2006;20063026.

4. Environment Agency. Flooding in England. A National Assessment of Flood Risk; 2009.

5. ICHARM: Global Trends in Water-Related Disasters: An Insight for Policymakers. International Centre for Water Hazard and Risk Management, World Water Assessment Programme, UNESCO, Paris, France; 2009.

6. Jongman $B$, Hochrainer-Stigler $S$, Feyen $L$, Aerts JCJH, Mechler R, Botzen WJW, et al. Increasing stress on disaster-risk finance due to large floods. Nature Clim Change. 2014;4(4):264-268.

DOI:http://dx.doi.org/10.1038/nclimate2124

7. Hannaford J, Hall J. Flood Risk in the UK: evidence of change and management responses. In: Kundzewicz Z, editor. Changes in flood risk in Europe. International Association of Hydrological Sciences - Special Publication 10 (Blue Book series); 2012.

8. The Scottish Government. The Future of Flood Risk Management in Scotland: A
Consultation Document. The Scottish Government; 2008. Accessed 11 November 2013.

Available:http://www.scotland.gov.uk/Publi cations/2008/02/13095729/8

9. McEwen L. Changing flood risk: Longerterm flood patterns and generating characteristics in Scotland 1200 to present. Newcastle upon Tyne: British Hydrological Society; 2010.

10. Werritty A, Black A, Duck R, Finlinson W, Shackley S, Crichton D. Climate Change, Flood Occurrences Review. Scottish Executive Environment Group Research Programme Research Findings No. 19.Scottish Executive, Edinburgh; 2002.

11. Connick A, Galley J. The River Nith Catchment Management Plan. Dumfries: SEPA; 2014.

12. Schanze J. Flood risk management - a basic framework. In Schanze J, Zeman E, Marsalek J, editors. Flood Risk Management: Hazards, Vulnerability and Mitigation Measures. Nato Science Series. Springer Netherlands. 2006;67. DOI: 10.1007/978-1-4020-4598-1_1

13. Cœur D, Lang $M$. Use of documentary sources on past flood events for flood risk management and land planning. $C R$ Geosci. 2008;340(9-10):644-650. DOI: 10.1016/j.crte.2008.03.001

14. Black AR, Burns JC. Re-assessing the flood risk in Scotland. Sci Total Environ. 2002;294(1-3):169-184.

DOI: http://dx.doi.org/10.1016/S00489697(02)00062-1

15. Pretorius $\mathrm{H}$, James $\mathrm{W}$, Smit J. A strategy for managing deficiencies of SWMM modeling for large undeveloped semi-arid watersheds. In Pragmatic Modeling of Urban Water Systems, Monograph 21, James W, Irvine KN, Joksimovic D, Li JY, McBean EA, Pitt RE, Vasconcelos JG, Wright SJ, Wu JS, eds. CHI Press, Canada, chapter 1; 2013.

16. Sothea K, Chansopheaktra S, Irvine K, Duval K. Phnom Penh sewer modeling and contaminant load estimates. Asian Journal of Water, Environment and Pollution. 2010;7(3):31-38.

17. Das S, Simonovic SP. Assessment of uncertainty in flood flows under climate change - the Upper Thames River basin (Ontario, Canada). $\mathrm{Br} \mathrm{J}$ Environ Clim Chang. 2012;2(4):318-338.

18. Bates PD, Horritt MS, Hunter NM, Mason D, Cobby, D. Numerical modelling of 
floodplain flow. John Wiley and Sons: Chichester, UK; 2005;271-297.

19. Néelz S, Pender G. Desktop review of 2D hydraulic modelling packages. Environment Agency Science Report, SC080035/SR; 2009.

20. Huang $Y$. Rapid flood risk assessment using GIS technology. Intl J River Basin Management. 2009;7(1):3-14. DOI: 10.1080/15715124.2009.9635365

21. Valyrakis $M$, Diplas $P$, Dancey $C L$. Entrainment of coarse particles in turbulent flows: An energy approach. J Geophys Res Earth Surf. 2013;118(1):42-53.

DOI: 10.1029/2012JF002354

22. Brunner GW. HEC-RAS hydraulic reference manual.US Army Corps of Engineers, Hydrologic Engineering Center. Davis: US; 2010.

23. Davis J, Dawson R, Hall J. Performancebased management of flood defence systems. Proceedings of the ICE - Water Management. 2004;157(1):35-44.

24. Kourgialas NN, Karatzas GP. Flood management and a GIS modelling method to assess flood-hazard areas - a case study. Hydrolog Sci J. 2011;56(2):212-225.

25. Sayers P, Galloway G, Penning-Rowsell E, Yuanyuan L, Fuxin S, Yiwei C, et al. Strategic flood management: ten 'golden rules' to guide a sound approach. Intl J River Basin Management. 2014;1-15.

26. Hall J, Penning-Rowsell E. Setting the Scene for Flood Risk Management. 2010;1-16.

27. Silva W, Dijkman JPM, Loucks DP. Flood management options for The Netherlands. Intl. J. River Basin Management. 2004; 2(2):101-112.

DOI: $10.1080 / 15715124.2004 .9635225$
28. Hooijer A, Klijn F, Pedroli GBM, Van Os AG. Towards sustainable flood risk management in the Rhine and Meuse river basins: synopsis of the findings of IRMASPONGE. River Res Appl. 2004;20(3): 343-357.

DOI: $10.1002 /$ rra.781

29. Tingsanchali T. Urban flood disaster management. Procedia Eng. 2012;32(0): 25-37. DOI:http://dx.doi.org/10.1016/j.proeng.201 2.01.1233

30. Kenyon W. Evaluating flood risk management options in Scotland: A participant-led multi-criteria approach. Ecol Econ. 2007;64(1):70-81. DOI: 10.1016/j.ecolecon.2007.06.011

31. Baan PJA, Klijn F. Flood risk perception and implications for flood risk management in the Netherlands. Intl. J. River Basin Management. 2004;2(2):113-122. DOI: $10.1080 / 15715124.2004 .9635226$

32. Werritty A, Houston D, Ball T, Tavendale A, Black, A. Exploring the Social Impacts of Flood Risk and Flooding in Scotland. Scottish Executive Environment Group Research Findings No. 32/2007; 2007.

33. Hall JW, Meadowcroft IC, Sayers PB, Bramley ME. Integrated flood risk management in England and Wales. Nat Hazards Rev. 2003;4(3):126-135.

34. Moodie S, McGregor L. Whitesands Flood Risk Appraisal. Jacobs Engineering: Dumfries; 2006.

35. Penning-Rowsell E, Viavattene C, Pardoe J, Chatterton J, Parker D, Morris J. The Benefits of Flood and Coastal Risk Management: A Handbook of Assessment Techniques. Flood Hazard Research Centre: Middlesex; 2010.

(C) 2015 Valyrakis et al.; This is an Open Access article distributed under the terms of the Creative Commons Attribution License (http://creativecommons.org/licenses/by/4.0), which permits unrestricted use, distribution, and reproduction in any medium, provided the original work is properly cited. 